\title{
MICROBIOLOGICAL TRANSFORMATIONS OF PROGESTERONE
}

\author{
ABDEL MONEM H. EL-REFAI, LOTFY A.R. SALLAM AND \\ ISMAIL A. EL-KADY \\ Microbiological Chemistry Lab., National Research \\ Centre, Cairo, U.A.R.
}

(Received February 1, 1969)

\begin{abstract}
Transformation of progesterone by various microorganisms such as actinomycetes, yeast and mould fungi of different 53 strains had been studied. 19 different strains was able to oxygenate progesterone at $\mathrm{C}_{11}$. The transformation products, other than $11 \alpha$-hydroxyprogesterone, which were formed by these active strains had been identified. These studies proved that the active organisms were capable of introduction of oxygen function at different positions other than position 11 of progesterone e.g. positions 17 and 21 . Side chain degradation reaction with and without lactone formation of ring $\mathrm{D}$ of progesterone had been also found to be performed by some of these organisms.
\end{abstract}

Of the many chemical changes brought about in steroids by microorganisms the one at $C_{11}$ is by far the most important. The microbial-11-alpha hydroxylations of progesterone, PETERSON and MURRAY (1), especially with Rhizopus arrhizus served as the initial impetus in the study of microbiological transformation from the practical and technical view. Hydroxylation of steroids in that strategic position is performed by many fungi other than Rhizopi. Several stimulatory reviews on this subject have been appeared during the last ten years e.g. Vischer and Wettstein (2), Peterson (3), VAN DYKE (4) and CAPEK et al. (5)

The present work aims to study the ability of different representatives of locally isolated microorganisms to introduce 11-alpha-hydroxyl group into progesterone. Identification of $11 \alpha$-hydroxyprogesterone as well as other transformation products formed by the active strains were further carried out in a trial to throw some light on the possible utilization of these reactions in the preparation of some cortical hormones.

\section{EXPERIMENTALS}

Organisms. The different organisms used in this work were collected from the centre of cultures of the Microbiological Chemistry Lab., N.R.C., 
Cairo. These strains were isolated from local habitats and identified through the American Type Culture Collection, Washington; the Centraalbureau Voor Schimmelcultures, Baarn (Holland) and the B.I.R.F. (England).

Cultivation. The medium formulated by CAPEK et al. (6) was used as a nutritive solution. This medium has the following composition ( $\mathrm{g} / \mathrm{liter}$ ): glucose, 40.0 ; peptone, $1.0 ; \mathrm{KH}_{2} \mathrm{PO}_{4}, 0.74 ; \mathrm{MgSO}_{4} \cdot 7 \mathrm{H}_{2} \mathrm{O}, 1.0$; Yeast extract, 1.0 and asparagine, 0.7. The $\mathrm{pH}$ was adjusted to 5.6. The cultivation was performed in 250-ml Erlenmeyer flasks each containing $50 \mathrm{ml}$ medium. The flasks were sterilized at 1 atmosphere for $30 \mathrm{~min}$, and inoculated with $2 \mathrm{ml}$ inoculum of a $48 \mathrm{hr}$ cultures of the pure organism. The culture flasks were agitated on a reciprocal shaker (110 strokes/min, amplitude $7 \mathrm{~cm}$ ) at $30^{\circ} \pm 2$ for $48 \mathrm{hr}$. Thereafter, $20 \mathrm{mg}$ of progesterone, dissolved in $1 \mathrm{ml} 96 \%$ ethyl alcohol, was added to each flask and fermentation was continued for another $72 \mathrm{hr}$.

Extraction. At the end of the fermentation period, the contents of each flask (medium + mycelium) were homogenized in a blender $(8,000 \mathrm{rpm})$ with two volumes of chloroform $(100 \mathrm{ml})$. The extraction was repeated three times in order to ensure that all the transformation products were extracted. The combined chloroform extracts were washed with half its volume 5\% sodium bicarbonate solution; followed by an equal volume distilled water, dried over anhydrous sodium sulphate, filtered, then distilled.

Analysis of the transformation mixtures. The residues obtained after evaporation of the chloroform extracts were dissolved separately in $5 \mathrm{ml}$ chloroform-methanol $(1: 1)$. Analysis was carried out by the thin-layer chromatographic technique on silica gel $G$ plates as described by the authours in the next article SALLAM et al. (7). The following two solvents: cyclohexane: chloroform : iso-propanol $(100: 50: 20)$ and cyclohexane: acetone: chloroform (75:25:20) proved to be satisfactory for the resolution of all the transformation products encountered during this work. The developed plates were sprayed with $\mathrm{I}_{2} / \mathrm{KI}$ solution. The fact that $11 \alpha$-hydroxyprogesterone gave a characteristic blue colour with this reagent was used to select the organisms capable of oxygenation of progesterone at $C_{11}$ position. The transformation products other than $11 \alpha$-hydroxyprogesterone were further identified by studying the thin-layer chromatographic picture of each product compared with the authentic steroids upon using different solvent systems and colour reagents (SALLAM) (T) et al.

\section{RESULTS AND DISCUSSION}

\section{Oxygenation of progesterone at $C_{11}$}

The data presented in Table 1 showed the ability of the different experimental organisms to transform progesterone to $11 \alpha$-hydroxyprogesterone. The presence of $11 \alpha$-hydroxylation was indicated by the sign $(+)$. The different strains of Rhizopus nigricans tested as well as most of the Aspergilli, except 
Table 1. The ability of different microorganisms to oxygenate the $\mathrm{C}_{11}$ of progesterone.

\begin{tabular}{|c|c|}
\hline Organism & $11 \alpha-\mathrm{OH}$ Prog. \\
\hline Streptomyces sp. A1 & --- \\
\hline Streptomyces sp. A2 & --- \\
\hline Streptomyces sp. A3 & --- \\
\hline Streptomyces sp. A4 & -- \\
\hline Streptomyces sp. A5 & --- \\
\hline Saccharomyces cerevisiae & -- \\
\hline Saccharomyces carlsbergensis & --- \\
\hline Saccharomyces delbruecki & -- \\
\hline Saccharomyces fermentati & --- \\
\hline Rhodotorula miniute & --- \\
\hline Torulopsis famata & --- \\
\hline Cryptococcus neoformans & --- \\
\hline Geotrichum candidum (Link) & --- \\
\hline Mucor fragilis (Bain) & + \\
\hline Cunninghamella echinulata (Curie \& Thom) & --- \\
\hline Verticillum dahliae (Klebahn-F. Zonatum V. Beyma) & --- \\
\hline Penicillium notatum (Westl) & $-\cdots$ \\
\hline Penicillium oxalicum (Curie \& Thom) & --- \\
\hline Penicillium requeforti $(\mathrm{P}-21-1)$ & --- \\
\hline Penicillium chrysogenum (Dierckx) & --- \\
\hline Penicillium brevi-compactum & + \\
\hline Cladosporium cladosporioides (Fres) de Vries powdery type & + \\
\hline Cladosporium herbarum (Link) & --- \\
\hline Helminthosporium speciferum (Bain) & -- \\
\hline Aspergillus niger (AMN) & -- \\
\hline Aspergillus niger (74) & -- \\
\hline Aspergillus niger $(3 \mathrm{~N})$ & + \\
\hline Aspergillus niger (58F) & + \\
\hline Aspergillus niger (73) & + \\
\hline Aspergillus niger (100) & + \\
\hline Aspergillus niger (200) & + \\
\hline Aspergillus niger (567) & + \\
\hline Aspergillus niger ( $1 \mathrm{R})$ & + \\
\hline Aspergillus niger (108) & + \\
\hline Aspergillus niger (37) & + \\
\hline Aspergillus fischeri (Wehmer) & + \\
\hline Aspergillus terrus & --- \\
\hline Aspergillus flavus & $-\cdots$ \\
\hline Aspergillus fumigatus (Fres) & $--\cdots$ \\
\hline Aspergillus ochraceus (Wilhelm) & + \\
\hline Aspergillus suniculosis $(518)^{a}$ & + \\
\hline Rhizopus nigricans (LTF) & + \\
\hline Rhizopus nigricans (YSF) ${ }^{a}$ & + \\
\hline Rhizopus nigricans (REF)' & + \\
\hline Fusarium oxysporium & --- \\
\hline Fusarium equiseti (Forma) & --- \\
\hline Fusarium semitectum & $-\ldots$ \\
\hline Fusarium sambucinum (Forma) & $-\ldots$ \\
\hline Alternaria tenuis (Nees) & --- \\
\hline Alternaria tenuis (Auct) & --- \\
\hline Gibberella fujikuroi (117) & --- \\
\hline Epicoccum purpurasces & + \\
\hline
\end{tabular}

2. These organisms are isolated and identified by the authors. 
Aspergillus niger AMN and 74; Asp. terrus; Asp. flavus and Asp. fumigatus, showed rather extensive ability to perform $11 \alpha$-hydroxylation. On the other hand, the strains of Fusarium spp., Alternaria spp., Streptomyces spp. and Yeast spp. fail to produce $11 \alpha$-hydroxylations. Moreover, the Penicillium spp. investigated except Pen. brevi-compactum were unable to carry out this reaction. These results are in close agreement with the findings of many authors e.g. DUlaney et al. (8), CAPEK and $\operatorname{HANC}(9,10)$.

\section{Transformation products other than $11 \alpha$-hydroxyprogesterone}

It was rather of interest to identify the transformation products, other than $11 \alpha$-hydroxyprogesterone, produced by the active strains. The results tabulated in Table 2 showed that almost every strain investigated seemed to possess a certain type remarkable activity in its steroid transforming reaction. That is, although all the Aspergilli gave $11 \alpha$-hydroxy and $6 \beta, 11 \alpha$-dihydroxyprogesterone derivatives, other products were detected with the various strains tested. For instance, with Asp. fischeri and Asp. suniculosis, 11 $\alpha$-hydroxyallopregnane was formed. The latter compound was also detected as a transformation product with Rhiz. nigricans LTF 127 and REF 129 respectively. Asp. niger 100 and 567, Asp. fischeri, Rhiz. nigricans REF 129 and Epicoccum purpurasces were able to introduce hydroxyl group at $\mathrm{C}_{21}$ of progesterone. Furthermore, 11 $\alpha$, 21-dihydroxyprogesterone was detected with Asp. niger 3N, 200, 567 and 1R, respectively. ZAFFARONI et al. (11) confirmed the microbiological 21-hydroxylation of several steroids by the use of Asp. niger. Furthermore, WEISZ et al. (12) and WIX et al. (13) found that a strain of Asp. niger was able to introduce both $11 \alpha$ and 21 hydroxyl groups simultaneously into progesterone, while RUBIN et al. (14) showed that Curvularia lunata affected $11 \beta, 21$ dihydroxylations of progesterone. Reactions of this type are of considerable importance since these two hydroxyl groups are constituents of most of the antiflamatory steroids, PETERSON (3)

Carbon 17 is another site of hydroxyl group representing an important constituent of the biologically significant adrenal cortical hormones and derivatives. Oxygenation at that position was successfully achieved by Cladosporium cladosporioides, Asp. niger 37 and 100, and Rhiz. nigricans REF 129. The microbiological introduction of the tertiary $17 \alpha$-hydroxyl group along with simultaneous introduction of the biologically important oxygen at $\mathrm{C}_{11}$ was also observed with the local strains, Clad. cladosporioides, Asp. niger 100 and 37, Asp. fischeri and Rhiz. nigricans REF 129. Progesterone was recorded to be transformed to $11 \alpha, 17 \alpha$-dihydroxyprogesterone derivative by Cephalothecium roseum, MEISTER et al. (15); Dactylium dendroides; Scopulariopsis brevicaulis and Tricothesium roseum; TIMOFEEVA et al. (16) and DULANEY and MCALEER (17).

An interesting reaction is that recorded with Clad. cladosporioides, Asp. niger 100 and Rhiz. nigricans REF 129 whereby progesterone was hydroxylated at $\mathrm{C}_{11}, \mathrm{C}_{17}$ and $\mathrm{C}_{21}$ positions to give $11 \alpha, 17 \alpha, 21$-trihydroxyprogesterone 
Table 2. Transformation of progesterone by the $11 \alpha$-hydroxylator microorganisms.

\begin{tabular}{|c|c|c|c|c|}
\hline \multirow[b]{2}{*}{ Organism } & \multicolumn{2}{|c|}{ Transformation } & \multicolumn{2}{|c|}{ Products $^{a}$} \\
\hline & $\begin{array}{l}\text { Mono- } \\
\text { hydroxy }\end{array}$ & Dihydroxy & Trihydroxy & Other products \\
\hline Mucor fragilis (Bain) & $11 \alpha ; 15 \alpha$ & $6 \beta, \quad 11 \alpha$ & --- & --- \\
\hline Penicillium brevi-compactum & $11 \alpha ; 15 \alpha$ & --- & --- & $\begin{array}{l}\text { testololactone } \\
\text { testosterone } \\
\text { androstendione }\end{array}$ \\
\hline $\begin{array}{l}\text { Cladosporium cladosporioides } \\
\text { (Fres, de Vries powdery type) }\end{array}$ & $\begin{array}{l}11 \alpha ; 11 \beta \\
17 \alpha\end{array}$ & $\begin{array}{l}6 \beta, 11 \alpha \\
11 \alpha, 17 \alpha\end{array}$ & $\begin{array}{l}11 \alpha, 17 \alpha, 21 \\
11 \beta, 17 \alpha, 21\end{array}$ & --- \\
\hline Aspergillus niger $(3 \mathrm{~N})$ & $11 \alpha$ & $\begin{array}{l}6 \beta, 11 \alpha \\
11 \alpha, 21\end{array}$ & --- & --- \\
\hline Aspergillus niger $(58 \mathrm{~F})$ & $11 \alpha$ & $6 \beta, 11 \alpha$ & --- & --- \\
\hline Aspergillus niger (73) & $11 \alpha$ & $6 \beta, 11 \alpha$ & --- & --- \\
\hline Aspergillus niger (100) & $\begin{array}{l}11 \alpha ; 17 \alpha ; \\
21\end{array}$ & $\begin{array}{l}6 \beta, 11 \alpha \\
11 \alpha, 17 \alpha\end{array}$ & $11 \alpha, 17 \alpha, 21$ & --- \\
\hline Aspergillus niger (200) & $11 \alpha$ & $\begin{array}{l}6 \beta, 11 \alpha \\
11 \alpha, 21\end{array}$ & --- & --- \\
\hline Aspergillus niger (567) & $11 \alpha ; 21$ & $\begin{array}{l}6 \beta, 11 \alpha \\
11 \alpha, 21\end{array}$ & --- & --- \\
\hline Aspergillus niger $(1 \mathrm{R})$ & $11 \alpha$ & $\begin{array}{l}6 \beta, 11 \alpha \\
11 \alpha, 21\end{array}$ & --- & --- \\
\hline Aspergillus niger (37) & $11 \alpha ; 17 \alpha$ & $\begin{array}{ll}11 \alpha, & 15 \beta \\
11 \alpha, & 17 \alpha\end{array}$ & --- & --- \\
\hline Aspergillus fischeri (Wehmer) & $\begin{array}{l}11 \alpha ; 11- \\
\text { hydroxy } \\
\text { allopreg- } \\
\text { nane; } 21\end{array}$ & $11 \alpha, \quad 17 \alpha$ & --- & testololactone \\
\hline $\begin{array}{l}\text { Aspergillus ochraceus } \\
\text { (Wilhelm) }\end{array}$ & $11 \alpha$ & $6 \beta, 11 \alpha$ & --- & --- \\
\hline Aspergillus suniculosis (518) & $\begin{array}{l}11 \alpha ; 11- \\
\text { hydroxy } \\
\text { allopreg- } \\
\text { nane }\end{array}$ & $6 \beta, 11 \alpha$ & --- & testololactone \\
\hline Rhizopus nigricans (YSF 128) & $11 \alpha$ & $6 \beta, 11 \alpha$ & --- & --- \\
\hline Rhizopus nigricans (REF 129) & $\begin{array}{l}11 \alpha ; 11 \alpha- \\
\text { hydroxy } \\
\text { allopregn- } \\
\text { ane; } 17 \alpha\end{array}$ & $\begin{array}{l}6 \beta, \quad 11 \alpha \\
11 \alpha, \quad 17 \alpha\end{array}$ & $11 \alpha, 17 \alpha, 21$ & --- \\
\hline Epicoccum purpurasces & $\begin{array}{l}11 \alpha ; 11 \beta ; \\
21\end{array}$ & $\begin{array}{l}6 \beta, 11 \alpha \\
11 \alpha, 21\end{array}$ & --- & --- \\
\hline
\end{tabular}

a Mono, di and trihydroxy=monohydroxylation, dihydroxylation and trihydroxylation of progesterone at the different recorded positions. 
(epicortisole). Furthermore, cortisole (11 $\beta, 17 \alpha$, 21-trihydroxyprogesterone was also produced with Clad. cladosporioides. According to the available literatures, the only report on the microbiological hydroxylation of progesterone at these three carbon atoms with Rhiz. nigricans and Cunninghamella blakesleeana was given by CIBA (18).

Other interesting reaction is the detection of the epimers $11 \alpha$; and $11 \beta$ hydroxylations with Clad. cladosporioides and Epic. purpurasces. Both of these bio-oxidations, viz., $11 \alpha$-hydroxylation of progesterone and $11 \beta$-hydroxylation of compound S by Curvularia lunata have been scaled up in large production plants as a mean of making the cortical hormones and their derivatives, SyUll and KITA (19). ShIRASAKa et al. (20) also reported the transformation of progesterone to $11 \alpha$ and $11 \beta$ hydroxyderivatives by Botrytis fabae. Moreover, CAPEK and HANK (10) showed that the proportion of $11 \alpha$, and $11 \beta$ epimers depended on steroid substrate. In progesterone, the best ratio obtained with Absidia orchidis was $11 \alpha: 11 \beta=7: 1$.

The microbiological side chain degradation with and without lactonization of ring D of progesterone was observed with Asp. fischeri, Asp. suniculosis and Pen. brevi-compactum. These findings are in harmony with PETERSON et al. (21) and FRIED et al. (22) who showed that $\mathrm{C}_{21}$-steroids such as progesterone, desoxycorticosterone and compound $\mathrm{S}$ could be converted to $\mathrm{Jt}^{\mathrm{i}}$ androstene 3, 17-dione, as well hydroxylated steroids and testololactone, using Gliocladium spp., Penicillia and Aspergilli. SEBEK et al. (23) also noted that Pen. lilacinum metabolized progesterone successively to $20 \beta$-hydroxy-4-prognen3-one, testosterone, androstenedione and testololactone, of wich testosterone and androstenedione were readily interconvertible.

The authors are greatly indebted to Prof. Dr. M. Abdel Aziz. Faculty of Science, Cairo Univ., Prof. Dr. H.G. Osman and Prof. Dr. M.B.E. Fayez, N.R.C., Cairo, for their interest and encouragement.

\section{REFERENCES}

1) D.H. Peterson and H.C. Murray, J. Am. Chem. Soc., 74, 1871 (1952).

2) E. Vischer and A. Wettstein, Advances in Enzymology, XX, 237 (1958).

3) D.H. Peterson, Biochemistry of Industrial Microorganisms, Rainbow, C., Rose. A.H., Academic press, London and New York (1963), p. 537.

4) D.C. Van DyKe, Mendel Bull., 12 (1966).

5) A. CAPEK, O. HANC and M. TAdra, Microbial Transformation of Steroids, W. Junk, Publisher-The Hague-The Netherlands (1966).

6) A. Capek, M. Tadra and J. Tuma, Folia Microbiol., Prague, 9, 380 (1964).

7) L. A.R. Sallam, A.H. El-Refai and I.A. El-Kady, J. Gen. Appl. Microbiol., 15, 309 (1969).

8) E.L. Dulaney, W.J. Mcaleer, H.R. Barkenmeyer and C. Hlavac, Appl. Microbiol, 3, $372(1955)$.

9) A. Capek and O. Hanc, Folia Microbiol., Prague, 5, 251 (1960). 
10) A. CAPec and O. Hanc, Folia Microbiol., Prague, 6, 237 (1961).

11) A. Zaffaroni, C.C. Campillo, F. Cordova and G. Rosenkranz, Experientia, 11. 219 (1955).

12) E. WeIsz, G. WIX and M. Bodanszky, Naturwissenschaften, 43, 39 (1956).

13) G. Wix, M. Natonek and M. Kovacs, Acta Microbiol. Acad. Sci., Hungary, 6, $19 \vec{i}$ (1959).

14) B.A. Rubin, C.C. Campillo, G. Hendricks, F. Cordoya and A. Zaffaroni, Bact. Proc., 33, (1956).

15) P.D. Meister, L.M. Reineke, R.C. Meeks, H.C. Murray, S.H. Eppstein, H.M. Leigh Osborn, A. Weintraub and D.H. Peterson, J. Am. Chem. Soc., 76, 4050 (1954).

16) A.G. Timofeeva, E.G. Grusakova and A.A. Shpingis, IZVEST. Akad. Nauk. S.S.S.R., Ser Biol., 26, 574-81 (1961).

17) E.L. Dulaney and W.J. Mcaleer, U.S. 2970085, Jan. 31 (1961).

18) CIBA Ltd., Brit. 816922, July 22, 1959 (C.A. 54, 1659 e (1960)).

19) G.M. Shull and D.A. Kita, J. Am. Chem. Soc., 77, 763, (1955).

20) M. Shirasaka, M. Tsuruta, A. Naito, S. Sugawara and M. Nakamura, Takamine Kenkyusho Nempo, 11, 52-6 (1960).

21) D.H. Peterson, S.H. Eppstein, P.D. Meister, H.C. Murray, H.M. Leigh, A. Weintraub and L.M. Reineke, J. Am. Chem. Soc., 75, 5768 (1953).

22) J. Fried, R.W. Thoma and A. Klingsberg, J. Am. Chem. Soc., 75, 5764 (1953).

23) O.K. Sebek, D.H. Peterson and L.M. Reineke, J. Bact., 83, 1327 (1962). 